\title{
Effects of Aphanomyces Root Rot on Carbohydrate Impurities and Sucrose Extractability in Postharvest Sugar Beet
}

\author{
Karen L. Klotz and Larry G. Campbell, USDA-ARS, Northern Crop Science Laboratory, P.O. Box 5677, Univer- \\ sity Station, Fargo, ND 58105-5677
}

\begin{abstract}
Klotz, K. L., and Campbell, L. G. 2009. Effects of Aphanomyces root rot on carbohydrate impurities and sucrose extractability in postharvest sugar beet. Plant Dis. 93:94-99.

Sugar beet (Beta vulgaris) roots with rot caused by Aphanomyces cochlioides often are incorporated into storage piles even though effects of disease on processing properties are unknown. Roots with Aphanomyces root rot were harvested from six fields over 2 years. For each field, roots with similar disease symptoms were combined and assigned a root rot index (RRI) value ( 0 to $100 ; 0$, no rot symptoms; 100 , all roots severely rotted). After 20 or 120 days storage at $4^{\circ} \mathrm{C}$ and $95 \%$ relative humidity, concentrations of the major carbohydrate impurities that accumulate during storage and sucrose extractability were determined. Root rot affected carbohydrate impurity concentrations and sucrose extractability in direct relation to disease severity symptoms. Generally, roots with active and severe infection (RRI $\geq 85)$ exhibited elevated glucose and fructose concentrations 20 and 120 days after harvest (DAH), elevated raffinose concentration 120 $\mathrm{DAH}$, and reduced sucrose extractability 20 and $120 \mathrm{DAH}$. Roots with minor or moderate disease symptoms (RRI 20 to 69), or damaged roots with no signs of active infection, had similar carbohydrate impurity concentrations and sucrose extractability after 20 and 120 days storage. Processing properties declined when RRIs exceeded 43, as determined by regression analysis, or when storage duration increased from 20 to 120 days. Results indicate that both disease severity and anticipated duration of storage be considered before Aphanomyces-infected roots are incorporated into storage piles.
\end{abstract}

Additional keywords: invert sugars

Sugar beet (Beta vulgaris L.) roots produced in the northern Midwest and western states of the United States are harvested in late autumn and stored in large piles cooled by ambient air until processed. Roots are stored up to 120 days in regions with moderate winters and up to 250 days in northern production regions such as Minnesota and North Dakota where winters are coldest (3). During storage, ongoing metabolism results in the loss of sucrose and the accumulation of carbohydrate impurities that hinder processing and reduce sucrose recovery rates. Carbohydrate impurities that form during storage are primarily the invert sugars, glucose and

Corresponding author: Karen L. Klotz

E-mail: karen.klotz@ars.usda.gov

The use of trade, firm, or corporation names is for the information and convenience of the reader. Such use does not constitute an official endorsement or approval by the United States Department of Agriculture or the Agricultural Research Service of any product or service to the exclusion of others that may be suitable.

Accepted for publication 1 October 2008.

\section{doi:10.1094/PDIS-93-1-0094}

This article is in the public domain and not copyrightable. It may be freely reprinted with customary crediting of the source. The American Phytopathological Society, 2009. fructose, and the trisaccharide, raffinose. These carbohydrate impurities are synthesized at the expense of sucrose and, during processing, increase the loss of sucrose to molasses, the sugar-containing syrup that remains after sucrose crystallization and from which further recovery of sucrose is not economically feasible (7). In addition, invert sugars degrade to colored compounds that hinder formation of white sugar, while raffinose reduces sucrose crystallization rate and alters sucrose crystal morphology, causing separation problems and delays in factory operations (7).

Sucrose extractability typically declines during storage because juice purity, i.e., the ratio of sucrose to total dissolved solids in root extracts, declines during storage. Sucrose extractability is a measure of the expected yield of sucrose after processing, relative to the sucrose present in the root. Many compounds affect sucrose extractability, although sodium, potassium, and amino nitrogen concentrations are typically the major impurities responsible for reduced sucrose recovery during processing $(6,7)$. Although sodium and potassium contents usually do not change during storage, amino nitrogen concentrations often increase (8). Loss of sucrose to respiration and conversion to other carbohydrates during storage also reduces the ratio of sucrose to total dissolved solids, thereby reducing sucrose extractability.
Storage rots exacerbate the formation of carbohydrate impurities and the decline in sucrose extractability during storage. Several pathogens, including Phoma betae Frank, Botrytis cinerea Pers. Ex Fr., and Penicillium species, cause root decay after harvest. These fungi metabolize sucrose and cause glucose and fructose concentrations and sucrose loss to respiration to increase in stored roots $(1,11)$. Root rots caused by fungal diseases that developed prior to harvest, however, can also be present when roots are placed into storage. The effect of these rots on carbohydrate impurity formation during storage and sucrose extractability during the processing of stored roots is largely unknown.

Roots containing Aphanomyces are typically incorporated into storage piles. Aphanomyces root rot is a common disease that causes a chronic rotting of the root from late June to the end of the growing season (13). The disease is caused by Aphanomyces cochlioides Drechs., an organism that is widely distributed throughout U.S. sugar beet production areas, is persistent in the soil, and is not easily controlled by agronomic practices. As a result, Aphanomyces root rot is a chronic problem for many growers and can become particularly severe in years or fields where warm, moist conditions occur (12).

Previously, we demonstrated that Aphanomyces root rot, if sufficiently severe, had a significant impact on respiration rate and sucrose loss for roots held in storage (2). Here, we examine the effect of Aphanomyces root rot on the formation of carbohydrate impurities during storage and sucrose extractability during processing. The purpose of this research is to (i) assist agriculturists who must decide when the severity of Aphanomyces root rot justifies not harvesting a field, and (ii) assist storage pile managers in determining if these roots should be incorporated into storage piles or segregated for early processing.

\section{MATERIALS AND METHODS}

Roots exhibiting varying symptoms of chronic Aphanomyces root rot were harvested from six commercial fields in three contiguous counties in western Minnesota (Clay and Norman counties) and eastern North Dakota (Traill County). Three fields (Clay-1, Clay-2, and Clay-3) were harvested in 2001; three fields (Clay-4, Norman-1, and Traill-1) were harvested in 
2002. Aphanomyces root rot was the predominant disease in all fields, although secondary infections by other causal organisms cannot be ruled out. Roots were harvested as previously described (2) and stored at $4{ }^{\circ} \mathrm{C}$ and $95 \%$ relative humidity for up to 120 days.

From each field, roots were divided into four groups based on the severity of disease symptoms, with each group comprised of 36 roots with similar symptoms. A root rot index (RRI) for each sample was calculated as previously described (2) using the 0 to 100 rating system of Windels and Nabben-Schindler (14) where 0 indicates no rot symptoms on any of the roots of a sample and 100 indicates complete rot on all roots of a sample. Because of differences in disease severity between years, RRIs for the four groups differed between 2001 and 2002. In 2001, RRIs ranged from 20 to 86. In 2002, RRIs ranged from 31 to 100. No symptomless roots were available in either year because of the severity of the disease in all fields. Roots within a group were randomly divided into three samples, each comprised of 12 roots, and these samples were the experimental units used for subsequent analysis.

Roots were sampled 20 and 120 days after harvest (DAH), with one 12-root sample per field analyzed at $20 \mathrm{DAH}$ and two 12-root samples per field analyzed at 120 DAH. For carbohydrate analysis, a $2 \mathrm{~mm}$ thick longitudinal section was taken from the center of each root and flash frozen in liquid nitrogen. Individual root sections from each 12-root sample were combined, lyophilized, and ground to a powder. Carbohydrates were extracted with refluxing $80 \%$ ethanol (9) and analyzed for fructose, glucose, raffinose, and sucrose concentration by high-performance liquid chromatography using lactose as an internal standard (4). Sucrose extractability was calculated as recoverable sugar concentration/sucrose concentration * 100 using the methods and equations described by Dexter et al. (6). Clear juice purity (CJP) was determined using a Rudolf Research Analytical (Hackettstown, NJ) Autopol 880 saccharimeter linked to a Rudolf Research Analytical J57 automatic refractometer. CJP was used to calculate recoverable sugar concentration (6).

The SAS GLM procedure (ver. 9.1; SAS Institute, Inc., Cary, NC) was used for the analysis of variance. Fields and disease severity groups were assumed to be fixed effects. LSDs were calculated when $F$ tests indicated significance at the 0.10 probability level. The $10 \%$ significance level was chosen over the frequently used 5 or $1 \%$ levels to reduce the probability of committing a type II error (5). In this study, the economic consequences of assuming disease severity groups are equal when, in fact, they were different (a type II error) are greater than concluding two groups are different when they are actually similar (a type I error). Increasing the probability of a type I error decreases the probability of committing a type II error. Data from 2001 and 2002 were analyzed separately since disease severity differed between years. Regression equations for relationships between root rot index and glucose, fructose, and raffinose concentrations, and sucrose extractability were determined with Origin data analysis software (ver. 7.5; OriginLab Corp., Northampton, MA). Roots with severe Aphanomyces root rot symptoms, but no apparent active rot at harvest, were not included in the relational data analysis.

\section{RESULTS}

Severity of Aphanomyces root rot symptoms differed in 2001 and 2002. In 2001, the root rot index (RRI) for roots grouped by the severity of disease symptoms ranged from 20 to 86 , with a mean RRI of 51 (Table 1). RRIs for the four disease severity groups in 2001 averaged 23,36 , 61, and 85. In 2002, RRIs for the four groups of roots ranged from 31 to 100 , with a mean RRI of 73 (Table 2). RRIs for the four groups in 2002 averaged 36, 62, 94 , and 99. In 2002, roots in groups 3 and 4 were severely damaged, with average RRIs of 94 and 99, respectively. The roots differed, however, in the activity of the disease organism at time of harvest. Roots in group 3 (Table 2) exhibited no symptoms of active infection. These roots were severely malformed, scarred, and stunted, but the damaged tissue was relatively dry, fibrous, and necrotic. In group 4 (Table 2), Aphanomyces infection was active as evidenced by the presence of brown to black watery lesions. Aphanomyces infection was active in all groups in 2001 (groups 1 to 4 , Table 1) as well as in groups 1 and 2 in 2002 (Table 2).

Glucose and fructose concentrations were elevated in roots with severe and active Aphanomyces infection, relative to roots with mild to moderate disease symptoms or roots with no symptoms of active infection, at 20 DAH in 2001 and 2002 and $120 \mathrm{DAH}$ in 2002 (Tables 1 and 2). At 20 DAH, roots with active infection and root rot indices of 84 or greater had glucose concentrations that were two- to fourfold greater and fructose concentrations that were 4- to 44-fold greater than roots with lower RRIs or without an active infection. After 120 DAH, mean glucose and fructose concentrations in roots with the most severe symptoms (mean RRI 99; group 4) were elevated, on average, four- and fivefold, respectively, in 2002 relative to roots with lower RRIs (Table 2). No significant increase in glucose or fructose concentration $120 \mathrm{DAH}$, however, was observed in 2001 (Table 1).

Glucose and fructose concentrations in roots with root rot indices between 20 and 69 , or in roots with no apparent active infection, were similar (Tables 1 and 2). In
2001 and 2002, roots from disease severity groups 1 to 3 were not significantly different in mean glucose or fructose concentration at 20 or $120 \mathrm{DAH}$, with one exception. In 2001, mean glucose concentration at 20 DAH was similar in roots with RRIs of 23 and 61 (groups 1 and 3) but was significantly lower in roots with an RRI of 36 (group 2).

Regardless of disease severity, glucose and fructose concentrations increased with prolonged storage. In the 100 days between sampling dates, mean glucose and fructose concentrations for all roots increased 2.3- and 3.5-fold, respectively, in 2001 (Table 1). In 2002, mean glucose and fructose concentrations increased 1.4- and 2.4-fold (Table 2).

Raffinose was present at much lower concentrations than glucose or fructose in all groups of Aphanomyces-infected roots. In 2001, raffinose concentration ranged from 0.15 to $1.75 \mathrm{~g}$ per $100 \mathrm{~g}$ of sucrose and was, on average, threefold lower than either glucose or fructose concentration 20 DAH and 15- and 19-fold lower than glucose and fructose concentrations, respectively, at 120 DAH (Table 1). In 2002, raffinose concentration ranged from 0.05 to $3.04 \mathrm{~g}$ per $100 \mathrm{~g}$ of sucrose and was, on average, two- and fourfold lower than fructose and glucose concentrations, respectively, at $20 \mathrm{DAH}$, and four- to fivefold lower than either invert sugar at 120 DAH (Table 2).

Raffinose concentration was significantly affected by severity of disease symptoms in both 2001 and 2002 (Tables 1 and 2). In 2001, raffinose concentration at 120 DAH was, on average, $58 \%$ higher in roots with moderate to severe symptoms of Aphanomyces (mean RRIs of 61 and 85; Table 1, groups 3 and 4) relative to roots with mean RRIs of 23 and 36 (Table 1, groups 1 and 2). In 2002, raffinose concentration at $120 \mathrm{DAH}$ was, on average, $61 \%$ higher in roots with symptoms of severe and active infection (mean RRI 99; Table 2 , group 4) relative to roots with more moderate symptoms (mean RRIs of 36 and 62; Table 2, groups 1 and 2). No increase in raffinose concentration, however, was noted in severely damaged roots after 20 DAH (Tables 1 and 2). In 2001, however, an elevation in raffinose concentration in moderately damaged roots (mean RRI 61; Table 1, group 3) relative to less damaged (mean RRI 23; group 1) or severely damaged (mean RRI 85; group 4) roots was observed.

Extractability of sucrose was significantly lower in roots with severe disease symptoms at $20 \mathrm{DAH}$ in 2001 and 120 DAH in 2001 and 2002 (Tables 1 and 2). At 20 DAH in 2001, sucrose extractability was reduced 14 to $17 \%$ in roots with a mean root rot index of 85 compared to roots with RRIs averaging 23 to 61 (Table 1). In 2002, disease severity had no effect on sucrose extractability at $20 \mathrm{DAH}$ (Table 
2). At $120 \mathrm{DAH}$, sucrose extractability was reduced $43 \%$ in 2001 (Table 1) and 9 to $15 \%$ in 2002 (Table 2) in roots with average RRIs of 85 or greater relative to roots with the lowest RRI.

Sucrose extractability was similar in roots with low to moderate disease symptoms, i.e., those roots with disease ratings of 20 to 69 . In 2001, there was no significant difference in sucrose extractability at 20 or 120 DAH between roots with average RRIs of 23 to 61 (Table 1, groups 1 to $3)$. In 2002, sucrose extractability was similar at both 20 and 120 DAH in roots with average RRIs of 36 and 62 (Table 2, groups 1 to 2 ).
The activity of infection at harvest had no apparent effect on sucrose extractability. In 2002, sucrose extractability was similar in roots with an average RRI of 94 and no active infection (Table 2, group 3 ) and roots with an average RRI of 99 and signs of active infection (group 4) at both 20 and $120 \mathrm{DAH}$.

Table 1. Root rot index, glucose, fructose, and raffinose content, and sucrose extractability in roots from three Clay County, MN, fields with Aphanomyces root rot after storage for 20 and 120 days after harvest (DAH) in 2001

\begin{tabular}{|c|c|c|c|c|c|c|c|c|c|c|}
\hline \multirow[b]{2}{*}{ Field } & \multirow[b]{2}{*}{ Group } & \multirow{2}{*}{$\begin{array}{c}\text { Root rot } \\
\text { index }(0-100)\end{array}$} & \multicolumn{2}{|c|}{ Glucose $^{\mathbf{a}}$} & \multicolumn{2}{|c|}{ Fructose $^{\mathbf{a}}$} & \multicolumn{2}{|c|}{ Raffinose $^{a}$} & \multicolumn{2}{|c|}{ Sucrose extractability $(\%)$} \\
\hline & & & 20 DAH & 120 DAH & 20 DAH & 120 DAH & 20 DAH & 120 DAH & 20 DAH & 120 DAH \\
\hline \multirow[t]{5}{*}{ Clay-1 } & 1 & 20 & 1.63 & 1.74 & 2.21 & 1.25 & 0.55 & 0.21 & 92.5 & 82.8 \\
\hline & 2 & 33 & 0.86 & 2.53 & 0.14 & 2.53 & 0.64 & 1.75 & 88.8 & 78.7 \\
\hline & 3 & 59 & 1.32 & 2.77 & 0.18 & 2.02 & 0.79 & 0.24 & 90.0 & 84.2 \\
\hline & 4 & 84 & 3.47 & 3.71 & 3.34 & 3.22 & 0.24 & 0.24 & 69.8 & 40.8 \\
\hline & Mean & 49 & 1.82 & 2.69 & 1.47 & 2.06 & 0.55 & 0.22 & 85.3 & 71.6 \\
\hline \multirow{5}{*}{ Clay-2 } & 1 & 26 & 1.45 & 6.15 & 0.33 & 11.34 & 0.70 & 0.25 & 95.1 & 68.4 \\
\hline & 2 & 40 & 0.74 & 5.52 & 0.14 & 12.89 & 0.68 & 0.15 & 90.4 & 66.2 \\
\hline & 3 & 67 & 1.65 & 5.97 & 1.66 & 11.81 & 0.63 & 0.44 & 90.7 & 54.4 \\
\hline & 4 & 85 & 3.06 & 4.13 & 5.21 & 6.85 & 0.42 & 0.50 & 80.3 & 52.7 \\
\hline & Mean & 54 & 1.72 & 5.44 & 1.83 & 10.72 & 0.61 & 0.34 & 89.1 & 60.4 \\
\hline \multirow[t]{5}{*}{ Clay-3 } & 1 & 23 & 2.24 & 0.96 & 0.79 & 0.37 & 0.43 & 0.22 & 89.5 & 87.3 \\
\hline & 2 & 37 & 1.05 & 2.29 & 0.13 & 1.18 & 0.60 & 0.33 & 94.5 & 82.5 \\
\hline & 3 & 58 & 1.64 & 3.31 & 0.84 & 2.34 & 0.67 & 0.35 & 87.8 & 81.8 \\
\hline & 4 & 86 & 3.42 & 12.35 & 4.20 & 11.36 & 0.29 & 0.36 & 80.9 & 41.6 \\
\hline & Mean & 51 & 2.09 & 4.73 & 1.49 & 3.81 & 0.50 & 0.32 & 88.1 & 73.3 \\
\hline \multirow{5}{*}{$\begin{array}{l}\text { Mean } \\
\text { (3 fields) }\end{array}$} & 1 & 23 & 1.78 & 2.95 & 1.11 & 4.32 & 0.56 & 0.22 & 92.3 & 79.5 \\
\hline & 2 & 36 & 0.88 & 3.44 & 0.14 & 5.27 & 0.64 & 0.23 & 91.2 & 75.8 \\
\hline & 3 & 61 & 1.53 & 4.02 & 0.89 & 5.39 & 0.70 & 0.34 & 89.5 & 73.4 \\
\hline & 4 & 85 & 3.32 & 6.73 & 4.25 & 7.14 & 0.31 & 0.37 & 77.0 & 45.1 \\
\hline & Mean & 51 & 1.88 & 4.29 & 1.60 & 5.53 & 0.55 & 0.29 & 87.5 & 68.5 \\
\hline \multirow[t]{3}{*}{$\operatorname{LSD}(0.10)^{\mathrm{b}}$} & Fields & 2 & NS & NS & NS & 3.61 & NS & 0.07 & NS & 9.1 \\
\hline & Groups & 2 & 0.34 & NS & 1.36 & NS & 0.14 & 0.08 & 5.9 & 10.5 \\
\hline & $\mathrm{F} \times \mathrm{G}$ & 5 & $\ldots$ & 4.67 & $\ldots$ & NS & $\ldots$ & 0.14 & $\ldots$ & 18.2 \\
\hline
\end{tabular}

a $g / 100 \mathrm{~g}$ sucrose.

${ }^{\mathrm{b}}$ LSD for comparing field, disease severity group, and interaction means within a column. NS indicates $F$ test for that source of variation was not significant $(P=0.10)$.

Table 2. Root rot index, glucose, fructose, and raffinose content, and sucrose extractability in roots from three fields with Aphanomyces root rot in Clay and Norman counties in Minnesota and Traill County in North Dakota after storage for 20 and 120 days after harvest (DAH) in 2002

\begin{tabular}{|c|c|c|c|c|c|c|c|c|c|c|}
\hline \multirow[b]{2}{*}{ Field } & \multirow[b]{2}{*}{ Group } & \multirow{2}{*}{$\begin{array}{c}\begin{array}{c}\text { Root rot } \\
\text { index }(0-100)\end{array} \\
\end{array}$} & \multicolumn{2}{|c|}{ Glucose $^{\mathbf{a}}$} & \multicolumn{2}{|c|}{ Fructose $^{\mathrm{a}}$} & \multicolumn{2}{|c|}{ Raffinose $^{a}$} & \multicolumn{2}{|c|}{ Sucrose extractability (\%) } \\
\hline & & & 20 DAH & 120 DAH & 20 DAH & 120 DAH & 20 DAH & 120 DAH & 20 DAH & 120 DAH \\
\hline \multirow[t]{5}{*}{ Clay-4 } & 1 & 46 & 3.27 & 2.04 & 0.34 & 1.61 & 1.03 & 1.52 & 89.0 & 89.4 \\
\hline & 2 & 53 & 5.32 & 3.62 & 0.72 & 2.35 & 0.05 & 1.04 & 89.0 & 90.7 \\
\hline & 3 & $93(D)^{b}$ & 6.94 & 5.71 & 1.05 & 3.18 & 1.44 & 1.45 & 87.7 & 82.5 \\
\hline & 4 & 99 & 9.14 & 17.25 & 14.99 & 15.27 & 0.59 & 1.67 & 84.2 & 62.9 \\
\hline & Mean & 73 & 6.17 & 7.22 & 4.28 & 5.61 & 0.78 & 1.42 & 87.5 & 81.4 \\
\hline \multirow[t]{5}{*}{ Norman-1 } & 1 & 31 & 2.31 & 3.31 & 0.17 & 3.55 & 1.67 & 1.59 & 95.1 & 92.5 \\
\hline & 2 & 63 & 3.80 & 4.62 & 0.26 & 2.96 & 3.04 & 1.36 & 93.0 & 84.6 \\
\hline & 3 & 95(D) & 5.58 & 10.12 & 2.42 & 6.57 & 1.89 & 2.31 & 90.5 & 88.8 \\
\hline & 4 & 99 & 8.23 & 23.76 & 4.70 & 25.44 & 1.09 & 2.90 & 95.9 & 83.4 \\
\hline & Mean & 73 & 4.98 & 10.45 & 1.89 & 9.63 & 1.92 & 2.04 & 93.6 & 87.3 \\
\hline \multirow[t]{5}{*}{ Traill-1 } & 1 & 32 & 2.18 & 2.74 & 0.13 & 2.46 & 1.36 & 1.28 & 93.2 & 91.1 \\
\hline & 2 & 69 & 1.95 & 2.39 & 0.24 & 1.60 & 1.23 & 0.94 & 91.7 & 90.4 \\
\hline & 3 & 94(D) & 2.70 & 6.13 & 0.28 & 7.21 & 1.87 & 1.61 & 93.3 & 77.8 \\
\hline & 4 & 100 & 16.16 & 12.54 & 9.58 & 10.58 & 1.11 & 1.66 & 81.4 & 86.1 \\
\hline & Mean & 74 & 5.75 & 5.95 & 2.56 & 5.46 & 1.40 & 1.37 & 89.9 & 86.3 \\
\hline Mean & 1 & 36 & 2.58 & 2.70 & 0.22 & 2.54 & 0.93 & 1.47 & 92.4 & 91.0 \\
\hline \multirow[t]{4}{*}{ (3 fields) } & 2 & 62 & 3.69 & 3.54 & 0.41 & 2.30 & 1.35 & 1.11 & 91.2 & 88.6 \\
\hline & 3 & 94(D) & 5.08 & 7.32 & 1.25 & 5.65 & 1.44 & 1.79 & 90.5 & 83.0 \\
\hline & 4 & 99 & 11.20 & 17.94 & 9.76 & 17.09 & 1.73 & 2.08 & 87.2 & 77.5 \\
\hline & Mean & 73 & 5.63 & 7.88 & 2.91 & 6.90 & 1.36 & 1.61 & 90.3 & 85.0 \\
\hline \multirow[t]{3}{*}{$\operatorname{LSD}(0.10)^{\mathrm{c}}$} & Fields & NS & NS & NS & NS & 3.43 & NS & 0.38 & NS & NS \\
\hline & Groups & 4 & 4.61 & 5.10 & 4.27 & 3.96 & NS & 0.44 & NS & 6.2 \\
\hline & $\mathrm{F} \times \mathrm{G}$ & 6 & $\ldots$ & NS & $\ldots$ & NS & $\ldots$ & NS & $\ldots$ & 10.7 \\
\hline
\end{tabular}

${ }^{\mathrm{a}} \mathrm{g} / 100 \mathrm{~g}$ sucrose.

${ }^{\mathrm{b}}$ (D) indicates roots had severe Aphanomyces symptoms but pathogen no longer appeared active (roots were dry).

${ }^{\mathrm{c}}$ LSD for comparing field, disease severity group, and interaction means within a column. NS indicates $F$ test for that source of variation was not significant $(P=0.10)$. 
Glucose and fructose concentrations at 20 and $120 \mathrm{DAH}$ were related to root rot index by second-order regressions (Fig. 1A to D). Regression equations were generated using the combined data from 2001 and 2002. Glucose concentration increased with root rot index for root rot indices greater than 45 at $20 \mathrm{DAH}$ and 43 at 120 DAH (Fig. 1A and B). Fructose concentration increased with root rot index for root rot indices greater than 47 at $20 \mathrm{DAH}$ and 44 at 120 DAH (Fig. 1C and D). Regression equations accounted for 51 to $64 \%$ of the variation in glucose and fructose concentrations with respect to RRI (Fig. 1A to D). The effect of increasing root rot index on glucose and fructose concentrations was greater at $120 \mathrm{DAH}$ than at $20 \mathrm{DAH}$, as evidenced by the greater curvature of the relationships at $120 \mathrm{DAH}$. For each unit increase in RRI, glucose concentration increased 1.6-fold more at $120 \mathrm{DAH}$ than at $20 \mathrm{DAH}$, while fructose concentration increased 1.5-fold more at $120 \mathrm{DAH}$ than at $20 \mathrm{DAH}$. Raffinose concentration was unrelated to RRI at $20 \mathrm{DAH}$ (Fig. 1E). At $120 \mathrm{DAH}$, raffinose was positively associated with RRI when RRIs were greater than 46, although the relationship explained only a small portion of the variation in raffinose concentration between samples $\left(R^{2}=0.29\right.$; Fig. $\left.1 \mathrm{~F}\right)$.

Sucrose extractability was inversely related to root rot index (Fig. 2). The decrease in sucrose extractability with increasing root rot index was 2.4-fold greater at $120 \mathrm{DAH}$ than at $20 \mathrm{DAH}$. Although significant, regression equations for relationships between RRI and sucrose extractability at 20 and 120 DAH explained only
17 to $20 \%$ of the variation in sucrose extractability for roots with different root rot indices.

\section{DISCUSSION}

Aphanomyces root rot affected concentrations of carbohydrate impurities and sucrose extractability of stored roots in relation to the severity of disease symptoms. Differences in carbohydrate impurity concentrations and sucrose extractability between roots differing in severity of disease symptoms, however, were generally only significant in roots with active and severe symptoms (RRI $\geq 85$ ). Generally, roots with active and severe infection exhibited elevated glucose and fructose concentrations at 20 and $120 \mathrm{DAH}$, elevated raffinose concentration at $120 \mathrm{DAH}$, and reduced sucrose extractability at 20 and

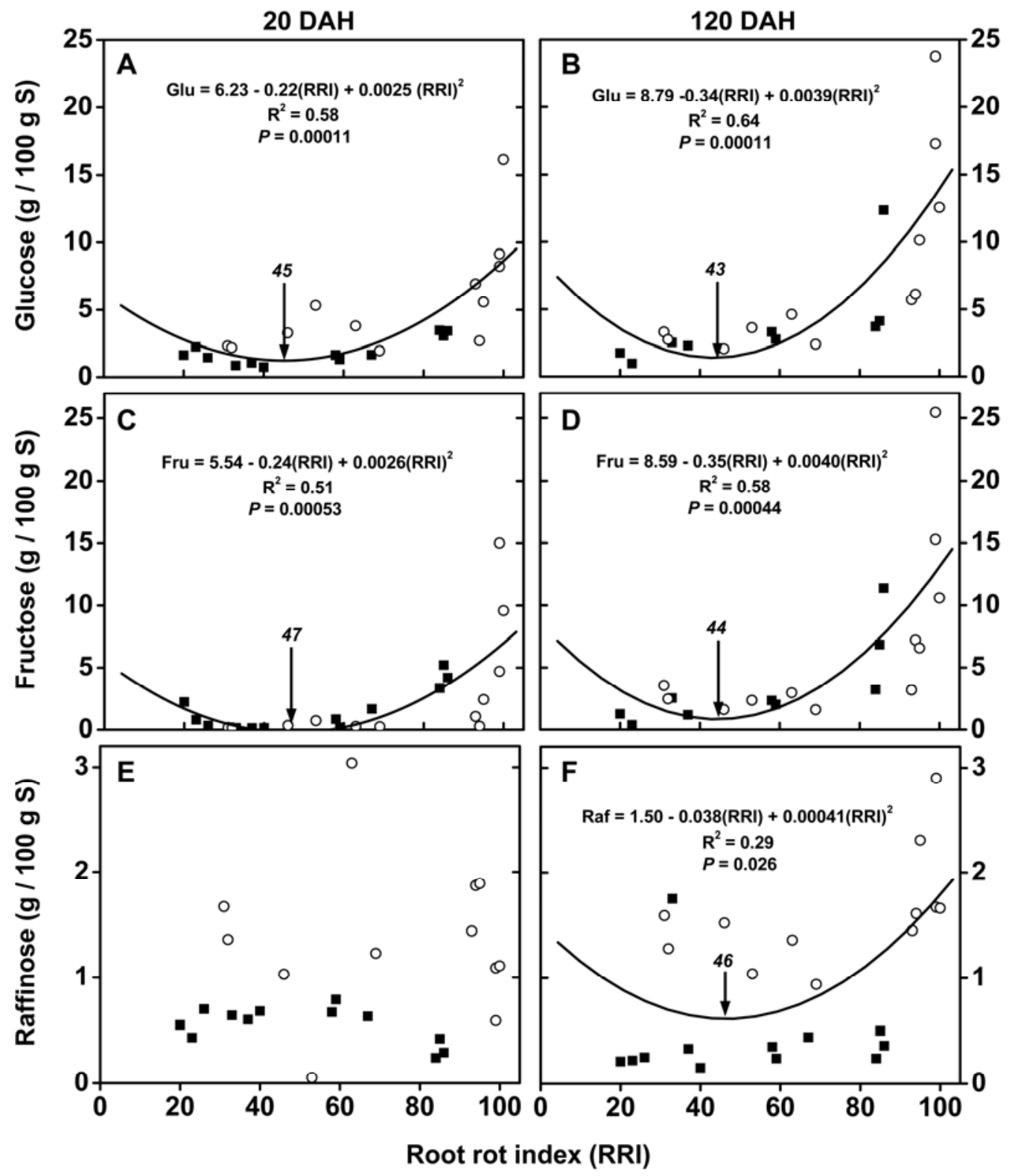

Fig. 1. Relationships between root rot index (RRI) and glucose (A, B), fructose (C, D), and raffinose (E, F) concentration for roots that exhibit symptoms of Aphanomyces infection and were stored for 20 (A, C, E) and 120 (B, D, F) days after harvest (DAH). Glucose, fructose, and raffinose concentrations are expressed in grams per $100 \mathrm{~g}$ of sucrose. Data obtained from roots collected in 2001 and 2002 are denoted by symbols $\boldsymbol{\square}$ and $\bigcirc$, respectively. Inflection point for each curve is noted with an arrow. 
120 DAH relative to roots with minor to moderate disease symptoms (RRI between 20 and 69). Although differences in glucose, fructose, and raffinose concentrations and sucrose extractability after storage for 20 and 120 days were observed in roots with minor or moderate disease severity symptoms or severely rotted roots that exhibited no signs of active infection, these differences were generally not significant.

Previously, roots with symptoms of active and severe Aphanomyces infection were found to have elevated storage respiration rate and reduced sucrose concentration relative to roots with minor to moderate disease symptoms at 20 and $120 \mathrm{DAH}$ (2). Roots with symptoms of active and severe root rot had respiration rates that were five- to sevenfold greater $20 \mathrm{DAH}$ and three- to fourfold greater $120 \mathrm{DAH}$ than roots with minor or moderate symptoms. Sucrose concentrations in these roots were reduced 28 to $36 \% 20 \mathrm{DAH}$ and 53 to $70 \% 120 \mathrm{DAH}$, relative to roots with minor or moderate symptoms. Similar to the present study, respiration rate and sucrose concentration were not significantly different between roots with minor or moderate disease symptoms or severely rotted roots with no signs of active infection.

Results of this study and that of Campbell and Klotz (2) indicate that roots with active and severe Aphanomyces infection cannot be stored without significant losses in extractable sucrose content during storage and processing. The elevated respiration rate and reduced sucrose concentration in roots with severe disease symptoms observed by Campbell and Klotz (2) indicate that these roots stored poorly during both short-term (20 DAH) and long-term (120 DAH) storage. The elevated glucose, fructose, and raffinose concentrations and reduced sucrose extractability observed in this study indicate that these roots also would process poorly after short- or longterm storage. With carbohydrate impurity concentrations comprising 7 to $27 \%$ of the total sugars present, and sucrose extracta- bility rates of 45 to $87 \%$, large losses to molasses would be expected during processing. Unacceptable color formation during evaporation of root extracts and a reduction in sucrose crystallization rate also could be expected due to high invert sugar concentration and elevated raffinose concentration (7).

The storability of roots with minor to moderate disease symptoms or Aphanomyces-damaged roots with no signs of active infection is less clear. Generally, respiration rate, sucrose, glucose, fructose, and raffinose concentrations, and sucrose extractability were not significantly different among roots with minor disease symptoms (root rot indices 20 to 46), roots with moderate disease symptoms (root rot indices 53 to 69), and damaged roots with no signs of active infection (this study and ref. 2 ), suggesting that storage and processing properties of these roots were similar. However, since disease-free or symptomless roots harvested from the same fields were not available for comparison, it is unknown whether storage and processing properties were adversely affected in roots with minor or moderate disease symptoms or Aphanomyces-damaged roots with no signs of active infection. Analysis of the relationships among root rot index, glucose concentration, fructose concentration, and raffinose concentration (Fig. 1), however, suggests that processing properties of roots with active Aphanomyces infection begin to decline when root rot indices exceed 43.

Aphanomyces root rot had a major effect on glucose and fructose accumulation during storage, and a considerably smaller effect on raffinose accumulation and sucrose extractability. Coefficients of determination for relationships between root rot index and glucose and fructose concentrations 20 and $120 \mathrm{DAH}$ ranged from 0.51 to 0.64 . The strong relationship between severity of disease symptoms and invert sugar accumulation in Aphanomycesinfected roots was perhaps not surprising since a strong association between invert sugar accumulation and disease severity has been demonstrated for fungal storage diseases (11). The increase in invert sugars in diseased roots is likely due to the activity of sucrose-degrading enzymes originating from the pathogen since pathogenderived enzymes are largely responsible for invert sugar accumulation in roots with fungal storage diseases (10). Raffinose concentration and sucrose extractability, in contrast, were weakly associated with root rot index, suggesting that other, unknown factors are largely responsible for differences in raffinose concentration and sucrose extractability observed in this study. Coefficients of determination for relationships between root rot index and raffinose concentration at $120 \mathrm{DAH}$, sucrose extractability at $20 \mathrm{DAH}$, and sucrose extractability at $120 \mathrm{DAH}$ were $0.29,0.20$, and 0.17 , respectively.

Regardless of the severity of Aphanomyces disease symptoms, processing properties of roots deteriorated with storage duration. In roots with severe disease symptoms, glucose concentration increased 60 to $103 \%$, fructose concentration increased 68 to $75 \%$, and sucrose extractability decreased 11 to $41 \%$ between 20 and $120 \mathrm{DAH}$. In roots with minor or moderate disease symptoms, or Aphanomycesdamaged roots with no sign of active infection, glucose concentration increased 19 to $150 \%$, fructose concentration increased 460 to $600 \%$, and sucrose extractability decreased 4 to $16 \%$ between 20 and 120 DAH. These data suggest that early processing of diseased roots is beneficial to minimize storage losses. Early processing also may allow diseased roots to be processed before they deteriorate to an extent to which processing is no longer economically or technically feasible.

The results from this study and that of Campbell and Klotz (2) indicate that Aphanomyces infection affects sugar beet root storage and processing properties. In these studies, storage properties deteriorated with increasing disease severity at

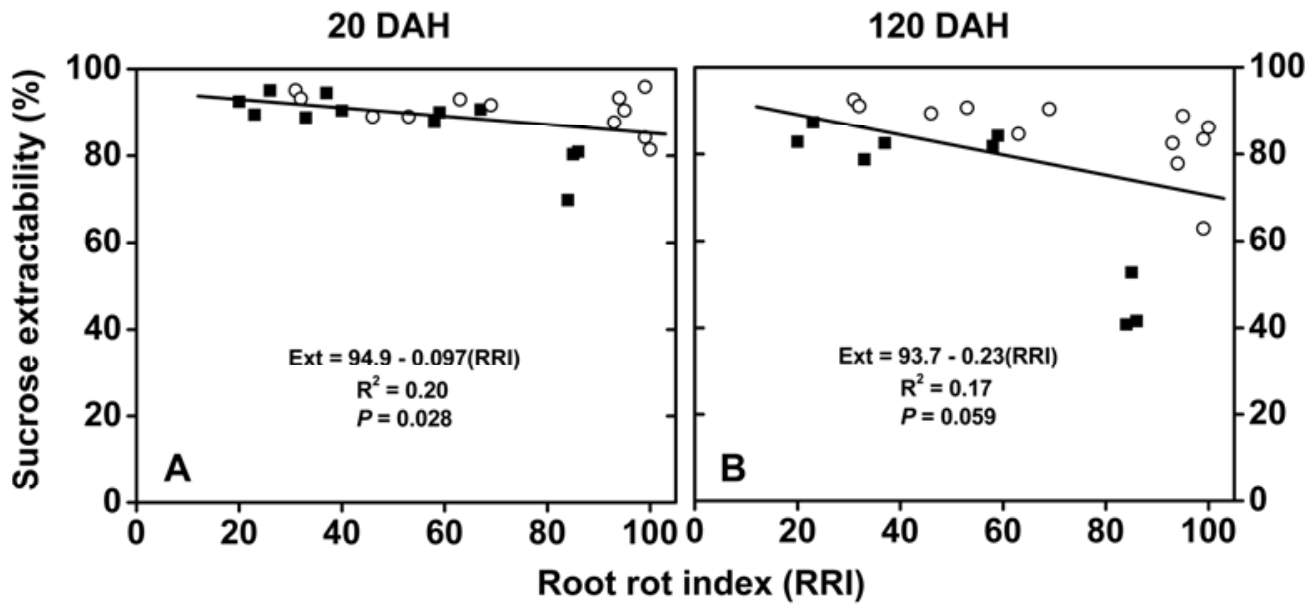

Fig. 2. Relationships between root rot index (RRI) and sucrose extractability for roots exhibiting symptoms of Aphanomyces infection that were stored for 20 and 120 days after harvest (DAH). Data obtained from roots collected in 2001 and 2002 are denoted by symbols $\mathbf{\square}$ and $\bigcirc$, respectively. 
root rot indices above 35 (2); processing properties deteriorated with increasing disease severity at root rot indices above 43 (this study). Further deterioration in processing properties occurred when storage duration increased from 20 to 120 days. These studies indicate that both disease severity and anticipated storage duration should be considered before roots with symptoms of Aphanomyces infection are incorporated into storage piles.

\section{ACKNOWLEDGMENTS}

The authors thank American Crystal Sugar Company personnel Allan Cattanach, Darin Vettern, and John Prigge for identifying fields for sampling and assistance with harvest; John Eide, Joe Thompson, and Nyle Jonason for technical support; and American Crystal Sugar Company and the Sugarbeet Research and Education Board of Minnesota and North Dakota for partial financial support.

\section{LITERATURE CITED}

1. Bugbee, W. M. 1982. Storage rot of sugar beet. Plant Dis. 66:871-873.

2. Campbell, L. G., and Klotz, K. L. 2006. Post- harvest storage losses associated with Aphanomyces root rot in sugarbeet. J. Sugar Beet Res. 43:113-128.

3. Campbell, L. G., and Klotz, K. L. 2006. Storage. Pages 387-408 in: Sugar Beet. A. P. Draycott, ed. Blackwell Publishing Ltd., Oxford, UK.

4. Campbell, L. G., and Klotz, K. L. 2007. Characterizing sugarbeet varieties for postharvest storage losses is complicated by environmental effects and genotype $\times$ environment interaction. Can. J. Plant Sci. 87:121-127.

5. Carmer, S. G. 1976. Optimum significance levels for application of the least significant difference in crop performance trials. Crop Sci. 16:95-99.

6. Dexter, S. T., Frakes, M. G., and Snyder, F. W. 1967. A rapid and practical method of determining extractable white sugar as may be applied to the evaluation of agronomic practices and grower deliveries in the sugar beet industry. J. Am. Soc. Sugar Beet Technol. 14:433454.

7. Dutton, J., and Huijbregts, T. 2006. Root quality and processing. Pages 409-442 in: Sugar Beet. A. P. Draycott, ed. Blackwell Publishing Ltd., Oxford, UK.

8. Kenter, C., and Hoffmann, C. 2007. Quality and storability of sugarbeet at early harvest. Zuckerindustrie 132:615-621.

9. Klotz, K. L., and Finger, F. L. 2002. Contribution of invertase and sucrose synthase isoforms to sucrose catabolism in developing sugarbeet roots. J. Sugar Beet Res. 39:1-24.

10. Klotz, K. L., and Finger, F. L. 2004. Impact of temperature, length of storage and postharvest disease on sucrose catabolism in sugarbeet Postharv. Biol. Technol. 34:1-9.

11. Mumford, D. L., and Wyse, R. E. 1976. Effect of fungus infection on respiration and reducing sugar accumulation of sugarbeet roots and use of fungicides to reduce infection. J. Am. Soc. Sugar Beet Technol. 19:157-162.

12. Papavizas, G. C., and Ayers, W. A. 1974 Aphanomyces species and their root diseases in pea and sugarbeet. U.S. Dep. Agric. Agric. Res. Serv. Tech. Bull. 1485.

13. Schneider, C. L., and Whitney, E. D. 1986 Black root. Page 17 in: Compendium of Beet Diseases and Insects. E. D. Whitney and J. E. Duffus, eds. American Phytopathological Society, St. Paul, MN.

14. Windels, C. E., and Nabben-Schindler, D. J. 1996. Limitations of a greenhouse assay for determining potential of Aphanomyces root rot in sugarbeet fields. J. Sugar Beet Res. 33:1-13. 